\title{
Degradation of Perchloroethylene and Dichlorophenol by Pulsed-Electric Discharge and Bioremediation
}

\author{
Dennis C. Yee, ${ }^{1}$ Sadhana Chauhan, ${ }^{1}$ Efim Yankelevich, ${ }^{2}$ Vitaly Bystritskii, ${ }^{2}$ \\ Thomas K. Wood ${ }^{1}$ \\ ${ }^{1}$ Department of Chemical and Biochemical Engineering, University of \\ California, Irvine, California 92697-2575; telephone: 714-824-8389; fax: \\ 714-824-2541; e-mail: tkwood@uci.edu \\ ${ }^{2}$ Department of Physics and Astronomy, University of California, \\ Irvine, California 92697-4575
}

Received 25 July 1997; accepted 9 January 1998

\begin{abstract}
Pulsed electric discharge (PED) and bioremediation were combined to create a novel two-stage system which dechlorinates the halogenated pollutants, 2,4dichlorophenol and perchloroethylene, with repetitive $(0.1-1 \mathrm{kHz})$, short pulse ( 100 ns), low voltage (40-80 kV) discharges and then mineralizes the less chlorinated products with aerobic bacteria. A $6.1 \mathrm{mM}$ aqueous dichlorophenol sample was cycled through the PED reactor (60 kV of applied pulsed voltage and $300 \mathrm{~Hz}) 6$ times, resulting in the release of $55 \%$ of the initial dichlorophenol chloride ions ( $1 \mathrm{mM} \mathrm{Cl}^{-}$removed each cycle). The respective average specific efficiency is $0.4-0.6 \mathrm{keV} /\left(\mathrm{Cl}^{-}\right.$ molecule). Pseudomonas mendocina KR1, which grows in minimal medium supplemented with phenol but not with dichlorophenol, increased in cell density in all cultures supplemented with the PED-treated DCP samples and yielded a maximum of two-fold additional $\mathrm{Cl}^{-}$released compared to the PED-related alone. The number of PED-treatment cycles, voltage, and frequency were also varied, showing that both cell densities and overall dichlorophenol dechlorination were highly dependent upon the number of PED-treatment cycles, rather than the tested voltages and frequencies. Using this two-stage treatment system, PED released $31 \%$ of the initial chloride ions from dichlorophenol (after three cycles at 40-45 $\mathrm{kV}$ and $1.2 \mathrm{kHz}$ ) while $P$. mendocina KR1 in the second stage increased dechlorination to $90 \%$. These results were corroborated by the $35 \%$ additional chloride release found with activated sludge cultures. Perchloroethylene $(0.6 \mathrm{mM})$ was similarly treated in a first-stage PED reactor ( $80 \%$ chloride removal after four cycles) followed by biodegradation of the dechlorinated products with a recombinant toluene o-monooxygenase-expressing Pseudomonas fluorescens strain. Gas chromatographic analysis showed that the PED reactor created less-chlorinated byproducts (i.e., trichloroethylene) that were removed $(74 \%)$ upon exposure to the recombinant bacterium. (c) 1998 John Wiley \& Sons, Inc. Biotechnol Bioeng 59: 438-444, 1998.
\end{abstract}

Keywords: bioremediation; plasma discharge; dichlorophenol degradation; perchloroethylene degradation

Correspondences to: Thomas K. Wood

Contract grant sponsors: University of California Toxic Substances Research and Teaching Program; Lucky Goldstar Industrial Systems Co.

Contract grant numbers: TS20616; LGIS-22936

\section{INTRODUCTION}

Highly chlorinated compounds, such as chlorophenols and perchloroethylene (PCE), are recalcitrant pollutants which threaten our environment. For example, 2,4-dichlorophenol (DCP) is a chlorinated aromatic that is a primary reagent in the synthesis of a variety of more highly chlorinated phenols (i.e., pentachlorophenol) and pesticides (i.e., 2,4-dichlorophenoxyacetic acid) (Kroschwitz, 1993). Because of its many applications in chemical synthesis, this aromatic is released into the environment through a wide range of industries. Consequently, DCP is recognized as an EPA priority pollutant identified in hazardous waste sites (Wentz, 1989) as well as in groundwater supplies, and water standard limits are set to $0.30 \mu \mathrm{g} / \mathrm{L}$ (United States Environmental Protection Agency, 1980). A National Organics Monitoring Survey detected DCP in over 50\% of 108 sampled finished drinking water sites (Syracuse Research Corporation, 1992). Damage to the nervous, epidermal, and skeletal systems are some of the effects observed in humans and animals exposed to DCP (Bleiberg et al., 1964; National Toxicology Program, 1989; Syracuse Research Corporation, 1992).

Another important pollutant is PCE, a chlorinated aliphatic which has been used as an industrial degreasing solvent and fumigant (Carter and Jewell, 1993). PCE is one of the five most frequently detected volatile organic compounds found in municipal groundwater supplies (Westrick et al., 1984), and it is one of 14 volatile organic compounds on the United States EPA's Priority Pollutant List (Carter and Jewell, 1993). Because this solvent is toxic and is a suspected carcinogen to humans (Leung et al., 1992), PCE is regulated under the Safe Drinking Water Act to a maximum contaminant level of $5 \mu \mathrm{g} / \mathrm{L}$. PCE is of particular concern because it is resistant to degradation by aerobic bacteria. In fact, only one aerobic bacterium has exhibited evidence of metabolizing PCE (Deckard et al., 1994) and those results have not been corroborated.

Bioremediation is an extremely attractive waste treatment 
process because microorganisms mineralize a variety of compounds, and bioremediation is an in situ process that minimizes transportation and disposal expenses. Although many highly halogenated compounds are recalcitrant to aerobic bacteria, less halogenated compounds can often be mineralized to $\mathrm{CO}_{2}$ and $\mathrm{H}_{2} \mathrm{O}$ at rates much faster than anaerobic bacteria. For example, Pseudomonas mendocina KR1 and Burkholderia cepacia G4 PR1 are able to use phenol, but not dichlorophenol, as a sole carbon and energy source. Similarly, the toluene $o$-monooxygenase (Tom) of B. cepacia G4 PR1 cometabolically degrades trichloroethylene (Nelson et al., 1987) to $\mathrm{CO}_{2}$ and $\mathrm{Cl}^{-}$, but is unable to catalyze degradation of the more chlorinated PCE. Because the degradation mechanism of anaerobic bacteria is by reductive dechlorination, anaerobic bacteria often do not mineralize the compounds to innocuous products such as $\mathrm{CO}_{2}$, $\mathrm{CH}_{4}$, and $\mathrm{H}_{2} \mathrm{O}$ (Freedman and Gossett, 1989). Consequently, some researchers have suggested the use of twostage reactors that utilize anaerobic biofilters in the first stage to produce less halogenated compounds that a secondstage filter of aerobic bacteria would be able to mineralize. Unfortunately, in such processes, the slow, anaerobic dechlorination remains the rate-limiting step. With some anaerobic cultures requiring over $30 \mathrm{~d}$ to degrade $100 \%$ of initial PCE (50 $\mu M)$ (Cabirol et al., 1996), continuous-flow reactors run with retention times over $1 \mathrm{~h}$ can only dechlorinate a fraction of the PCE in the feed stream (Enzien et al., 1994; Fathepure and Tiedge, 1994). To achieve faster dechlorination rates of recalcitrant pollutants, an abiotic process, such as the pulsed-electric discharge (PED) reactor, can be used in place of the anaerobic biofilter in a similar two-stage system.

The PED reactor is one form of an advanced oxidation process that uses non-thermal pulsed plasma in which medium-voltage electricity $(40-80 \mathrm{kV})$ is pulsed through an array of electrodes to generate a stream of secondary electrons within a cylindrical column and dehalogenate pollutants in an aqueous-feed stream. These secondary electrons (or streamer discharge) collide with $\mathrm{H}_{2} \mathrm{O}$ and $\mathrm{O}_{2}$ in the column, producing free radicals (i.e., $\mathrm{OH} \cdot$ and $\mathrm{H} \cdot$ ), hydrated electrons $\left(\mathrm{e}_{\mathrm{aq}}^{-}\right)$, ozone, and ultraviolet radiation with sufficient energy (e.g., 1-10 keV) to cleave, for example, a C-Cl bond, resulting in less-chlorinated products. Similar electric discharge reactors using mega-voltages have been used to effectively treat gas-phase volatile organic compounds, including trichloroethylene and perchloroethylene (up to $99.8 \%$ and $85.4 \%$ removal, respectively) (Gentile and Kushner, 1995; Shah et al., 1995; Virden et al., 1992). However, when used to treat pollutants in bulk water, these irradiation processes are much less effective, demanding mega-voltage outputs and wasting energy by heating the bulk water. The higher density and dielectric constant of water compared to air require electric field strengths that are 10 -fold greater, which results in sparking and poor propagation of the streamer discharge. For example, in air, the range in which secondary electrons possess $10-100 \mathrm{eV}$ is $1000-6000 \mathrm{~nm}$ from the discharge source and decreases to
1-10 nm in water (Adamczewski, 1969). To treat liquids under these conditions, systems have been developed for TCE (Cooper et al., 1993), PCE (Cooper et al., 1993; Getoff, 1990), and chlorinated phenols (Getoff and Solar, 1988) in bulk water with either a large-area, high-energy electron beam (1.5-3 MeV) (Cooper et al., 1993) or low-impedance, high-current, short-pulse accelerators to create 1-2 MV nanosecond pulses in an electrode gap less than $10 \mathrm{~cm}$ (Bystritskii et al., 1997). Unfortunately, to achieve 100\% dechlorination, these approaches both involve significant installation, maintenance, and operating costs (Bystritskii et al., 1997).

This work demonstrates the feasibility of a two-stage remediation process that first utilizes a novel PED reactor to dechlorinate aqueous pollutants using voltages (up to 80 $\mathrm{kV}$ ) much lower than the mega-voltages of high-energy electron beams and high-current accelerators (Cooper et al., 1993; Getoff, 1990). Efficient dechlorination of chlorinated aromatic and aliphatic model compounds (i.e., DCP and TCE) at these lower voltages is accomplished using an unique inlet feed system that, rather than treating bulk water, utilizes an atomizer to introduce the pollutant into the reactor as an aerosol mist. Because the organic pollutant is concentrated at the surface of each aerosol droplet (liquid atomization increases the surface area), the ionizing species interact efficiently with the pollutant at the air-liquid boundary. Hence, effective dechlorination results at these lower voltages because discharge sparking is minimized and streamer generation is enhanced. The less chlorinated effluent from the PED reactor was then biodegraded by aerobic microorganisms, which can mineralize many of the PED reactor byproducts.

\section{MATERIALS AND METHODS}

\section{Bacterial Strains and Culture Conditions}

Pseudomonas mendocina KR1 and P. fluorescens 279TOM-S (Yee et al., 1998) were routinely cultured in 250 $\mathrm{mL}$ Erlenmeyer flasks, containing $25 \mathrm{~mL}$ of either LuriaBertani medium (Sambrook et al., 1989) or modified M9 glucose minimal medium (Rodriguez and Tait, 1983) without chloride $\{10 \%$ (v/v) chloride-free salts stock solution $\left[\mathrm{Na}_{2} \mathrm{HPO}_{4}, 56.8 \mathrm{~g} / \mathrm{L} ; \mathrm{KH}_{2} \mathrm{PO}_{4}, 30 \mathrm{~g} / \mathrm{L} ;\left(\mathrm{NH}_{4}\right)_{2} \mathrm{HPO}_{4}, 12.3\right.$ $\mathrm{g} / \mathrm{L}], 1 \%(\mathrm{v} / \mathrm{v}) 0.01 \mathrm{M \textrm {CaSO } _ { 4 }}$, and $1 \%(\mathrm{v} / \mathrm{v}) 0.1 \mathrm{M} \mathrm{\textrm {MSO } _ { 4 }}$ added to either untreated or PED-treated DCP $\}$ in a New Brunswick Scientific Co. (Edison, NJ) Series 25 shaker at $250 \mathrm{rpm}$ and $30^{\circ} \mathrm{C}$. Reclaimed activated sludge, obtained from the Irvine Ranch Water District (Irvine, CA), was also cultured at $30^{\circ} \mathrm{C}$ in the modified, chloride-free M9 glucose minimal medium after washing a $10 \mathrm{~mL}$ sample with the chloride-free minimal medium by centrifuging at $10,000 \mathrm{~g}$ for $1 \mathrm{~min}$ at room temperature in a Beckman Instruments, Inc. (Fullerton, CA) J2-21 centrifuge. After decanting the supernatant, the sludge was resuspended in the same volume of chloride-free medium. 
Pseudomonas fluorescens 2-79TOM-S degradation of PED-treated PCE was performed by first harvesting a 25 $\mathrm{mL} \mathrm{LB}+400 \mu \mathrm{g} / \mathrm{mL}$ kanamycin $+2 \mathrm{~m} M$ salicylate overnight culture. The cell density of the overnight culture was first measured, and a culture volume was collected which would yield the equivalent of $25 \mathrm{~mL}$ at $\mathrm{A}_{600}=0.5$. The collected volume of cells was centrifuged $10,000 \mathrm{~g}$ for $1 \mathrm{~min}$ at room temperature, and then resuspended in $1 \mathrm{~mL}$ fresh LB medium. The $1 \mathrm{~mL}$ cell resuspension was immediately added to $60 \mathrm{~mL}$ serum vials containing $25 \mathrm{~mL}$ of PEDtreated PCE and $2 \mathrm{~m} M$ sodium salicylate. After the serum vials were sealed with Teflon ${ }^{\circledR}$-lined silicon septa and aluminum crimp tops, the vials were shaken at room temperature for $16 \mathrm{~h}$. Autoclaved cells $(20 \mathrm{~min})$ at the same cell density were also added to a 5.1:1 mixture of PCE and TCE and shaken for $17 \mathrm{~h}$ as a negative control for adsorption.

\section{Pulsed-Electric Discharge Reactor}

A diagram of the general PED reactor system is shown in Figure 1. The reactor chamber of the original reactor (PED \#1) consisted of a hollow, Teflon ${ }^{\circledR}$-coated Lucite cylinder (20 cm inner diameter, $150 \mathrm{~cm}$ height) with a set of axiallyoriented intermeshed electrodes placed in the center of the chamber. An atomizer with a maximum throughput of 2 $\mathrm{gal} / \mathrm{h}$ (with $30 \mathrm{psi}$ air) was mounted at the top of the reactor, and the effluent was collected at the bottom. The larger reactor (PED \#2) was similarly constructed using a Pyrex cylinder $(25 \mathrm{~cm}$ inner diameter, $150 \mathrm{~cm}$ height $)$ with an atomizer capable of 4-10 gal/h throughputs (with 20-70 psi air). In addition to the original installation of the atomizer at

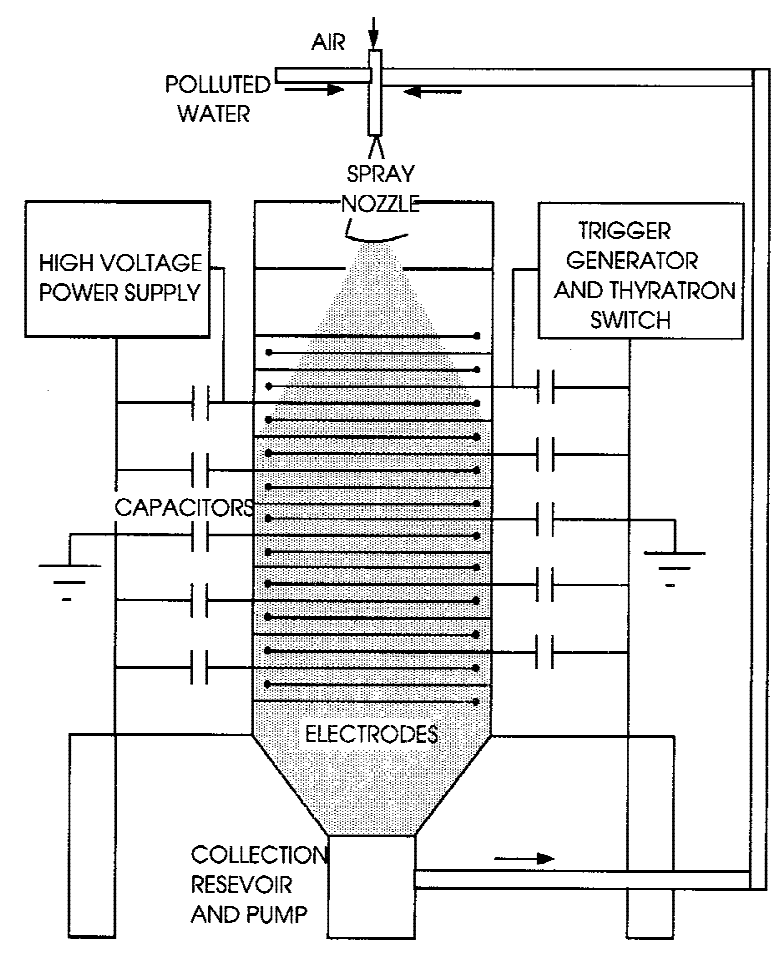

Figure 1. Schematic of the PED reactor. the reactor top, the residence time of the pollutants could be increased in PED \#2 by placing the atomizer on the reactor bottom. The pulsed, high-voltage power system for both reactors consisted of a DC power supply, an inductive choke, hydrogen thyratron trigger generator, thyratron bias supply, and a pulse-forming network of $50 \Omega$ cables in parallel. All DCP and PCE samples were processed using PED \#1, except for PED \#2 processing of the PCE samples obtained for treatment by $P$. fluorescens 2-79TOM-S.

DCP $(6.1 \mathrm{mM})$ in $500 \mathrm{~mL}$ volumes was treated through the PED reactor in which the applied voltage and pulsed discharge frequency were varied between 40 and $80 \mathrm{kV}$ and 300 to $1200 \mathrm{~Hz}$, respectively. After the initial pass through the PED reactor, $10 \mathrm{~mL}$ of the collected effluent was sampled and the remainder was re-introduced into the PED reactor up to 6 times. The effect of cycle number on PCE $(0.6 \mathrm{~m} M)$ was similarly determined by processing through five treatment cycles at $80 \mathrm{kV}$ and $300 \mathrm{~Hz}$. The PED-treated PCE, which was incubated with $P$. fluorescens 2-79TOM-S, was processed in PED \#2 at $60 \mathrm{kV}, 385 \mathrm{~Hz}, 30$ psi air by injecting $1 \mathrm{~mL}$ of pure $\mathrm{PCE}$ and $1 \mathrm{~L}$ of water.

\section{Chloride Ion Analysis}

Because of organic interferences with a selective chlorideion probe, chloride ions released from PED reactor treatment and/or microbial treatment were quantified using the spectrophotometric procedure of Bergmann and Sanik (1957) as described previously (Yee and Wood, 1997). Chloride ion concentrations greater than $1.5 \mathrm{~m} M$ were measured by diluting the sample 10-fold before adding the $\mathrm{Hg}$ $(\mathrm{SCN})_{2}$ and $\mathrm{Fe}\left(\mathrm{NH}_{4}\right)\left(\mathrm{SO}_{4}\right)_{2}$ reagents.

\section{Gas Chromatography Analysis}

The DCP remaining in PED treated samples was determined by gas chromatograph analysis of pentane extracts. The underivatized samples were analyzed as described previously (Yee and Wood, 1997) using a Varian 3600 gas chromatograph equipped with a flame ionization detector and a $1 \%$ SP1240-DA on 100/120 mesh Supelcoport packed column from Supelco.

Examination of products resulting from PED-treated PCE incubated with $P$. fluorescens 2-79TOM-S was performed by gas chromatograph analysis of the pentane-extracted cultures. After extracting each culture by shaking with $25 \mathrm{~mL}$ pentane for $10 \mathrm{~min}$, a $2 \mu \mathrm{L}$ sample was injected into a Hewlett Packard (Palo Alto, CA) 5890 Series II gas chromatograph (injector: $190^{\circ} \mathrm{C}$, detector: $210^{\circ} \mathrm{C}$, column: $130^{\circ} \mathrm{C}, 30 \mathrm{~mL} / \mathrm{min} \mathrm{N}_{2}$ ) equipped with an electron capture detector and an Alltech (Deerfield, IL) 0.1\% AT-1000 on 80/100 Graphpac packed column.

\section{RESULTS}

\section{First-Stage PED Reactor Dechlorination of DCP and PCE}

DCP was initially treated with the PED reactor using various voltage, frequencies, and process cycles to determine 
the most important parameter affecting dechlorination. The initial $(0 \mathrm{~h})$ data points of Figure 2 indicate the free chloride ions generated from PED reactor treatment at different conditions. These results indicate that the number of times the sample is cycled through the reactor has a greater impact upon dechlorination than voltages and frequencies varied from $40-60 \mathrm{kV}$ and $600-1200 \mathrm{~Hz}$, respectively. The effect of treatment cycle number upon DCP dechlorination was further investigated by processing a $6.1 \mathrm{~m} M$ DCP sample through the PED reactor from 1 to 6 times at $60 \mathrm{kV}$ and 300 Hz. Figure 3 shows a linear dependence of dechlorination; each pass through the PED reactor removed $1.0 \mathrm{mM} \mathrm{Cl}^{-}$so that after six cycles $55 \%$ of the total chloride was released. GC analysis of DCP samples processed through six cycles showed the removal of $94 \%$ DCP (data not shown). After each PED treatment cycle, the color of the effluent was observed to change from clear (no treatment) to aqua green (after six cycles).

Chloride ions released from the treatment of PCE with the PED reactor also demonstrated a linear dependence upon the cycle number. PCE treated at $80 \mathrm{kV}$ and $385 \mathrm{~Hz}$ generated $0.5 \mathrm{mM} \mathrm{Cl} \mathrm{Cl}^{-}$after each pass through the discharge reactor (Fig. 4). After four treatment cycles, $80 \%$ of the total chlorine associated with the PCE was released as free chloride.

\section{Second-Stage Bacterial Mineralization of PED-Treated DCP and PCE}

The ability of bacteria to mineralize the dechlorinated products of the DCP samples initially treated by the PED reactor was examined using bacteria known to metabolize phenol, such as $P$. mendocina KR1. Whereas $P$. mendocina KR1 could not grow on untreated DCP (i.e., DCP not treated through the PED reactor), minimal growth was observed in all cultures containing the PED-treated DCP as the sole carbon and energy source, regardless of the cycle number, discharge frequency, and voltage (Fig. 5). Similarly, while cultures supplemented with PED-treated samples (three cycles, $40 \mathrm{kV}, 1.2 \mathrm{kHz}, 30 \%$ dechlorination) produced an additional $65 \%$ dechlorination after $4 \mathrm{~d}$, cultures containing untreated DCP did not result in any additional dechlorination (Fig. 2).

These DCP results were also corroborated by studies with reclaimed activated sludge (which also did not grow on untreated DCP, data not shown). Activated sludge addition to PED-treated DCP (six cycles) resulted in an additional $35 \%$ chloride release over samples without sludge (Fig. 6).

PED-processed PCE was also further dechlorinated upon bacterial incubation with toluene ortho-monooxygenase (Tom)-expressing $P$. fluorescens 2-79TOM-S (tom $A^{+} B^{+}$under control of the salicylate-induced $\mathrm{p}_{\text {nah }}$ promoter). Because Tom does not degrade PCE, gas chromatograph analysis of PED-processed PCE that was exposed to the TCE-degrading bacterium confirmed that PCE (retention time, $\mathrm{RT}=6.4 \mathrm{~min}$ ) was relatively unchanged (as measured by the absolute peak height) from the analogous

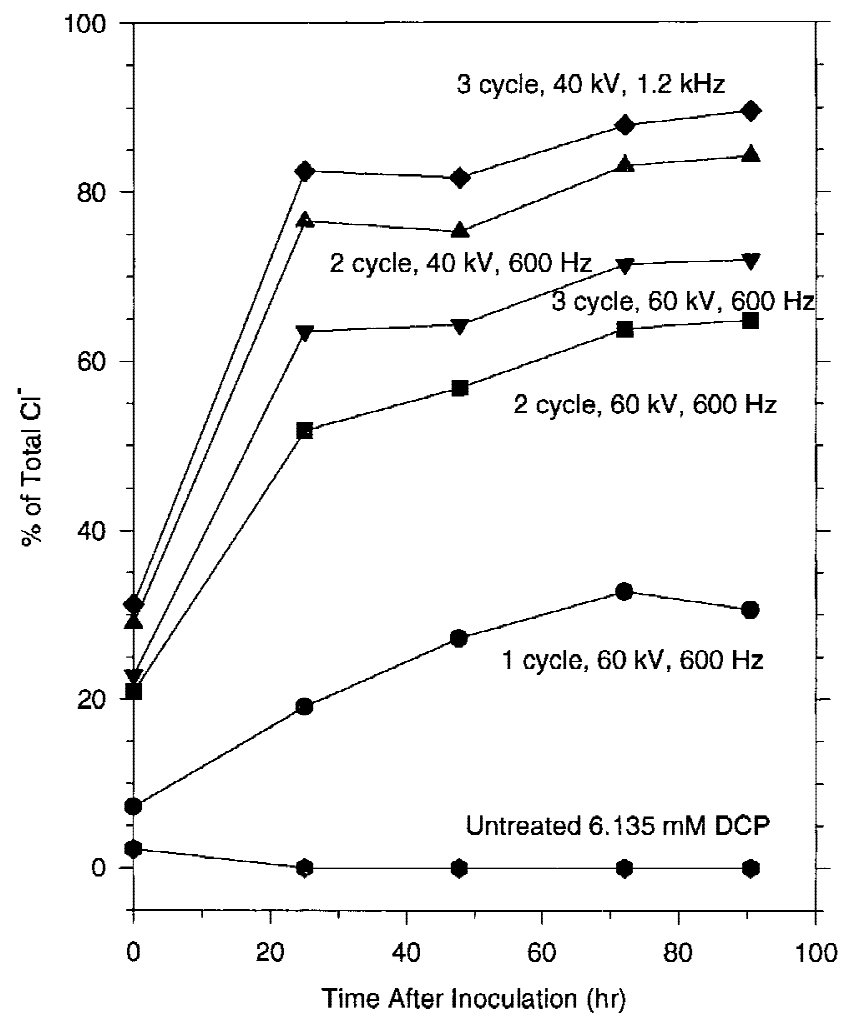

Figure 2. Pseudomonas mendocina KR1 dechlorination of PED-treated DCP. Each data point represents an average of two flasks.

sample unexposed to $P$. fluorescens 2-79TOM-S (Figs. 7a and $b)$. On the other hand, an observed peak (RT $=1.7$ min) with the same retention time as TCE decreased by $76 \%$ after an overnight incubation with $P$. fluorescens 279TOM-S (calculated after normalizing the PCE peak heights). Likewise, degradation of unidentified compounds

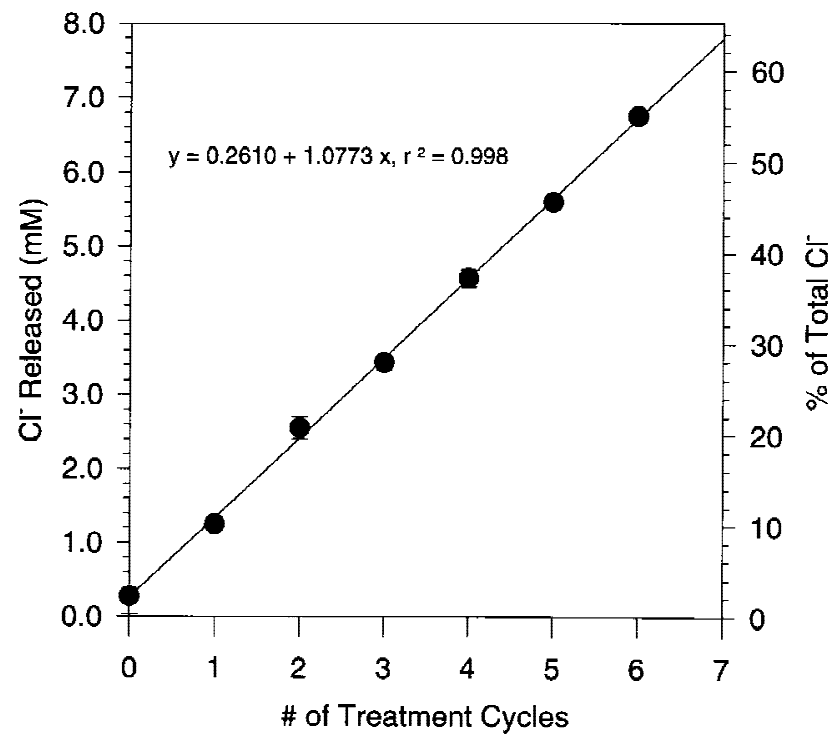

Figure 3. Chloride removal after PED-treatment of DCP at $60 \mathrm{kV}$ and $300 \mathrm{~Hz}$. Each data point represents an average of two measurements. 


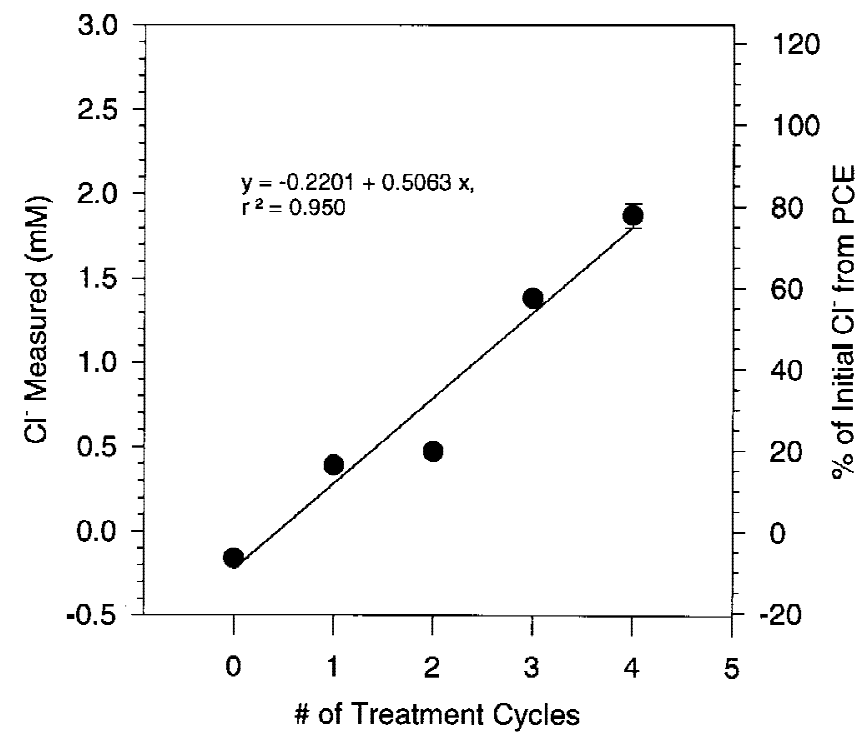

Figure 4. Chloride removal after PED-treatment of PCE at $80 \mathrm{kV}$ and $385 \mathrm{~Hz}$. Each data point represents an average of three measurements, with standard deviations shown.

with peaks at $\mathrm{RT}=2.4$ and 3.9 min was observed, and a bacterial-degradation byproduct was detected in the form of a new peak with $\mathrm{RT}=7.2 \mathrm{~min}$. In contrast, the concentration of PCE and TCE was not significantly altered by exposure to heat-inactivated $P$. fluorescens $2-79$ TOM-S cells (18\% and $12 \%$ reduction, respectively). Hence, the disappearance of the TCE peak was due to biological oxidation by Tom in P. fluorescens 2-79TOM-S.

\section{DISCUSSION}

The PED reactor is an effective remediation technology for the rapid dechlorination of compounds that are recalcitrant to bioremediation. These preliminary results confirm that the PED reactor is capable of dechlorinating DCP and PCE with voltages and currents generated from a standard $110 \mathrm{~V}$ electrical outlet. The extent of dechlorination of the model pollutants can be controlled by the number of cycles the samples are passed through the PED reactor. Rather than recycling the sample through the reactor, however, the same effect may be accomplished by increasing the residence time or by connecting multiple reactors in series. In addition, because the PED reactor is the first stage of a two-stage system, complete dechlorination leading to increased electrical costs and formation of unwanted byproducts is undesirable. The ability to easily control the extent of dechlorination facilitates the optimization of the PED reactor operation with regards to minimizing operating expenses and enhancing the second-stage mineralization efficiency.

These results not only confirm that this non-thermal, medium-voltage reactor is capable of dechlorinating compounds several times faster than anaerobic processes (i.e., min vs. h/d), but that the required electrical costs are much lower than other advanced oxidation techniques used to

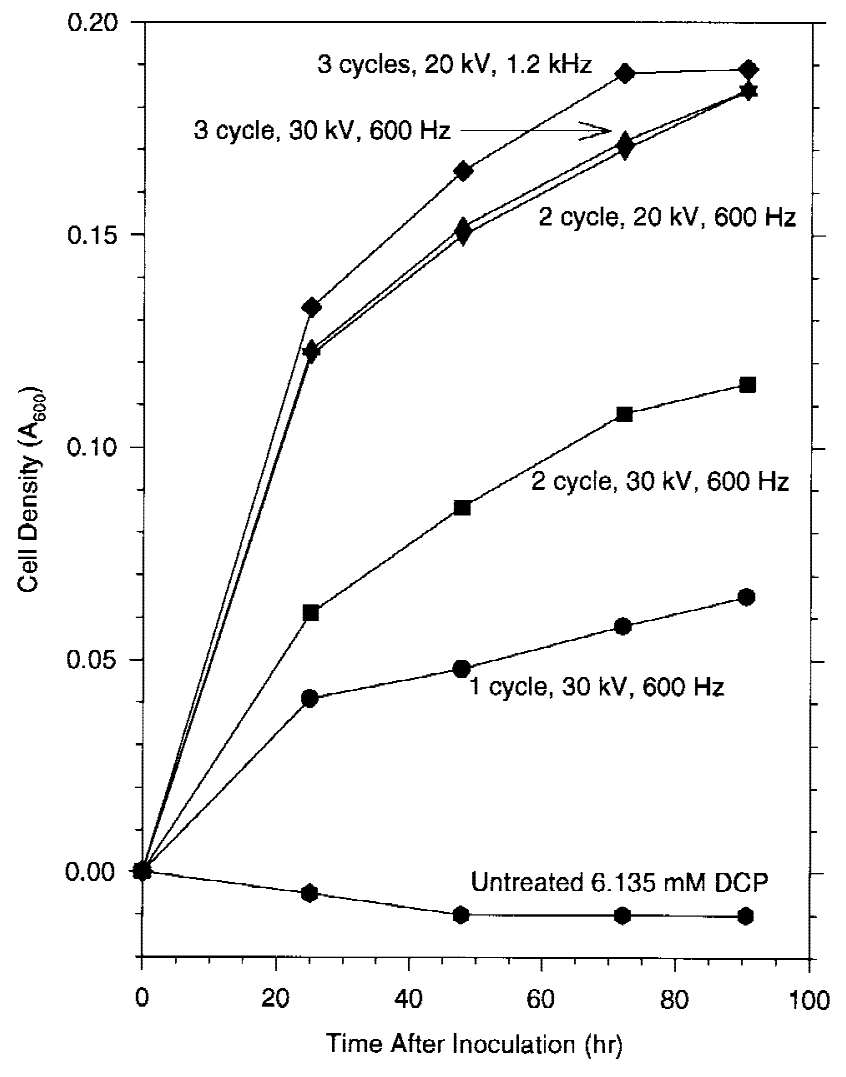

Figure 5. Pseudomonas mendocina KR1 cell density upon incubation with PED-treated DCP. Each data point represents an average of two flasks.

treat aqueous wastes. For example, as measured by the specific-energy cost required to degrade one molecule of pollutant, $\mathrm{S}_{\mathrm{c}}$, the PED reactor operates at a cost $\left[\mathrm{S}_{\mathrm{c}}(\mathrm{DCP})=\right.$ $\left.0.6 \mathrm{keV} / \mathrm{Cl}^{-}, \mathrm{S}_{\mathrm{c}}(\mathrm{PCE})=1.5 \mathrm{keV} / \mathrm{Cl}^{-}\right]$up to two orders of magnitude lower than that of 4-chlorophenol remediation by pulsed, kilojoule discharges in bulk water $\left(\mathrm{S}_{\mathrm{c}}=40 \mathrm{keV} /\right.$ $\mathrm{Cl}^{-}$) (Bystritskii et al., 1997). The PED reactor is, therefore, a practical alternative to dehalogenation by anaerobic bacteria.

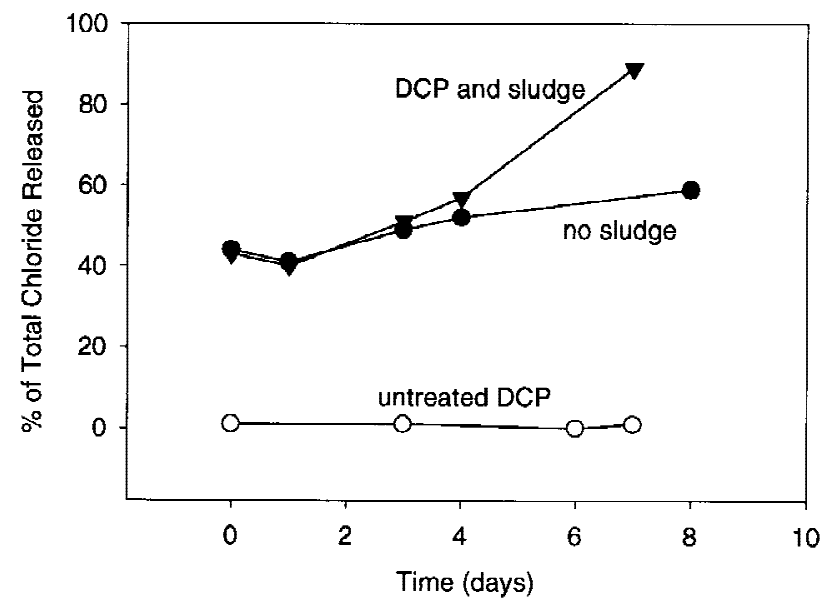

Figure 6. Activated sludge dechlorination of PED-treated DCP (six cycles). Each data point represents an average of two flasks. 
a)

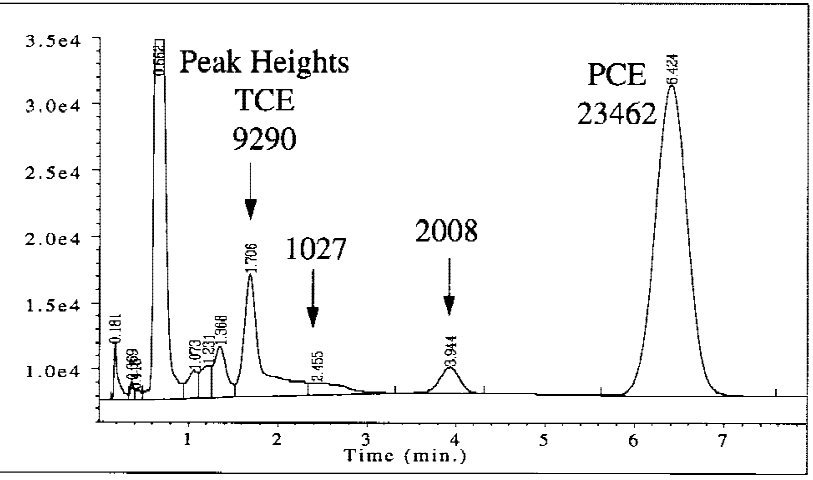

b)

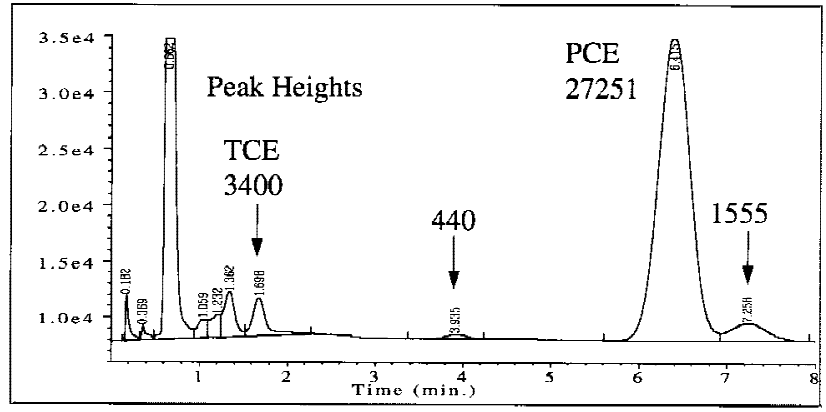

Figure 7. Gas chromatogram of treated PCE. (a) PED-treated PCE incubated (16 h) without bacteria. (b) Gas chromatogram of PED-treated PCE incubated $(16 \mathrm{~h})$ with $2 \mathrm{~m} M$ salicylate-induced $P$. fluorescens 279TOM-S. The retention time of TCE was $1.7 \mathrm{~min}$, and the retention time of PCE was 6.4 min. Peak heights of each compound shown.

The observed $P$. mendocina KR1 growth indicates that dechlorinated carbon and energy sources such as phenol and benzene were produced by the PED reactor. However, because the maximum cell density achieved in cultures supplemented with PED-treated DCP was only $20 \%$ of the maximum growth observed in phenol-supplemented cultures (data not shown), these results suggest that the PED operating parameters were not optimized for bioremediation. Bacterial growth may also have been restricted by toxic PED byproducts, such as the unidentified compounds that colored the PED effluent. In addition, because the chloride and GC data suggest that one chlorine atom was removed from each DCP molecule after six cycles (suggesting the generation of mono-chlorophenols), P. mendocina KR1 may not be the most appropriate bacterium to mineralize the predominating, less-chlorinated compounds.

The ability of aerobic bacteria to degrade the lesschlorinated PED reactor products demonstrates the feasibility of this two-stage treatment concept. The elucidation of how factors such as the effect of voltage, pulse frequency, and residence time affect the PED reactor dehalogenation products will be instrumental in the further design and scale-up of this first stage process. The identification of the PED reactor products would enable the efficient determination of the appropriate bacteria or bacterial consortia required for second-stage mineralization. The non-specific mechanism of action of the PED reactor and the powerful enzyme systems of microorganisms, therefore, can be utilized in the design of a low-cost remediation process capable or treating a wide range or mixed pollutants.

We thank Chris Kinner of the Irvine Ranch Water District for supplying activated sludge samples.

\section{References}

Adamczewski, I. 1969. Ionization, conductivity and breakdown in dielectric liquids. Taylor \& Francis, London.

Bergmann, J. G., Sanik, J. Jr. 1957. Determination of trace amounts of chlorine in naptha. Anal. Chem. 29: 241-243.

Bleiberg, J., Wallen, M., Brodkin, R., Applebaum I. L. 1964. Industrially acquired porphyria. Arch. Dermatol. 89: 793-797.

Bystritskii, V. M., Yankelevich, Y., Wessel, F., Gonzales, A., Olson, T., Wood, T. K., Yee, D. C., Puchkarev, V., Rosocha, L. 1997. Application of streamer discharge for polluted water remediation. In: W. J. Cooper, K. E. O'Shea, and R. D. Curry (eds.), Environmental applications of ionizing radiation, in press.

Cabirol, N., Perrier, J., Jacob, F., Fouillet, B., Chambon, P. 1996. Role of methanogenic and sulfate-reducing bacteria in the reductive dechlorination of tetrachloroethylene in mixed culture. Bull. Environ. Contamin. Toxicol. 56: 817-824.

Carter, S. R., Jewell, W. J. 1993. Biotransformation of tetrachloroethylene by anaerobic attached-films at low temperatures. Water Res. 27: $607-615$.

Cooper, W. J., Meacham, D. E., Nickelsen, M. G., Lin, K., Ford, D. B., Kurucz, C. N., Waite, T. D. 1993. The removal of tri- (TCE) and tetrachloroethylene (PCE) from aqueous solution using high energy electrons. J. Air \& Waste Manage. Assoc. 43: 1358-1366.

Deckard, L. A., Willis, J. C., Rivers, D. B. 1994. Evidence for the aerobic degradation of tetrachloroethylene by a bacterial isolate. Biotechnol. Lett. 16: 1221-1224.

Enzien, M. V., Picardal, F., Hazen, T. C., Arnold, R. G., Fliermans, C. B. 1994. Reductive dechlorination of trichloroethylene and tetrachloroethylene under aerobic conditions in a sediment column. Appl. Environ. Microbiol. 60: 2200-2204.

Fathepure, B. Z., Tiedge, J. M. 1994. Reductive dechlorination of tetrachloroethylene by a chlorobenzoate-enriched biofilm reactor. Environ. Sci. Technol. 28: 746-752.

Freedman, D. L., Gossett, J. M. 1989. Biological reductive dechlorination of tetrachloroethylene and trichloroethylene to ethylene under methanogenic conditions. Appl. Environ. Microbiol. 55: 2144-2151.

Gentile, A. C., Kushner, M. J. 1995. Plasma remediation of perchloroethylene in humid gas streams. J. Appl. Physics. 78: 2977-2980.

Getoff, N. 1990. Decomposition of biological resistant pollutants in water by irradiation. J. Radiat. Phys. Chem. 35: 432-439.

Getoff, N., Solar, S. 1988. Radiation induced decomposition of chlorinated phenols in water. J. Radiat. Phys. Chem. 31: 124-130.

Gov't Doc No. HE 20.7918:91/14 Research Corporation 1992. Toxicological profile for 2,4-dichlorophenol. U.S. Public Health Service, Washington, D.C.

Kroschwitz, J. I. (ed.) 1993. Encyclopedia of chemical technology, 4th ed., vol. 6. Wiley, New York.

Leung, S. W., Watts, R. J., Miller, G. C. 1992. Degradation of perchloroethylene by Fenton's reagent: Speciation and pathway. J. Environ. Qual. 21: 377-381.

National Toxicology Program 1989. Toxicology and carcinogenesis studies of 2,4-dichlorophenol in $\mathrm{F} 344 / \mathrm{N}$ rats and $\mathrm{B}_{6 \mathrm{C}} 3 \mathrm{~F}_{1}$ mice (feed studies). U.S. Department of Health and Human Services, Public Health Service, National Institutes of Health, Research Triangle Park, NIH Publication \#89-2808.

Nelson, M. J. K., Montgomery, S. O., Mahaffey, W. R., Pritchard, P. H. 1987. Biodegradation of trichloroethylene and involvement of an aro- 
matic biodegradative pathway. Appl. Environ. Microbiol. 53: 949-954.

Rodriguez, R. L., Tait, R. C. 1983. Recombinant DNA techniques: An introduction. Benjamin/Cummings Publishing, Menlo Park, CA.

Sambrook, J., Fritsch, E. F., Maniatis, T. 1989. Molecular cloning, a laboratory manual, 2nd ed. Cold Spring Harbor Laboratory Press, Cold Spring Harbor, NY.

Shah, R. R., Garcia, R. E., Jeffs, J. T., Virden, J. W., Heath, W. O. 1995. Initial field test of high-energy corona process for treating a contaminated soil-offgas stream, vol. PNL-9224. National Technical Information Service, Springfield, VA.

United States Environmental Protection Agency 1980. Ambient water quality criteria for 2,4-dichlorophenol. National Technical Information Service, Springfield, IL. EPA 440/5-80-042.

Virden, J. W., Heath, W. O., Goheen, S. C., Miller, M. C., Mong, G. M.,
Richardson, R. L. High-energy corona for destruction of volatile organic contaminants in process off-gases. (1992). Presented at Nuclear and Hazardous Waste Management Spectrum '92, Boise, ID.American Nuclear Society, Inc., LaGrange Park, IL.

Wentz, C. A. 1989. Hazardous waste management. McGraw-Hill, New York.

Westrick, J. J., Mello, J. W., Thomas, R. F. 1984. The groundwater supply survey. J. Am. Water Works Assoc. 76: 52-59.

Yee, D. C., Maynard, J., Wood, T. K. 1998. Rhizoremediation of trichloroethylene by a recombinant, root-colonizing Pseudomonas fluorescens strain expressing toluene ortho-monooxygenase constitutively. Appl. Environ. Microbiol. 64: 112-118.

Yee, D. C., Wood, T. K. 1997. 2,4-Dichlorophenol degradation using Streptomyces viridosporus T7A lignin peroxidase. Biotechnol. Prog. 13: $53-59$. 